DOI 10.5216/ia.v46i3.65170

\title{
AS INTERFACES DA FIGURA DO PROFESSOR: CAMINHOS E DESCAMINHOS DA (DES)PROFISSIONALIZAÇÃO DOCENTE
}

\author{
Cintia Bárbara Silva Borges \\ União Metropolitana de Educação e Cultura (UNIME), Lauro de Freitas, Bahia, Brasil \\ ItAMARAY NASCIMENTO CleOMENDES dos SANTOS \\ Universidade Federal da Bahia (UFBA), Salvador, Bahia, Brasil
}

\begin{abstract}
Resumo: O presente artigo, inicialmente, tem por finalidade discutir acerca das interfaces da figura docente, no que concerne à ética profissional, ao processo de (des)profissionalização e aos caminhos e descaminhos percorridos, assim como visa apresentar os percursos dessa formação, apontando os dilemas, possibilidades, embates e ajustes. Nesse sentido, buscamos aclarar e responder esses tensionamentos, os quais são fortemente evidenciados na contemporaneidade. Portanto, alguns questionamentos circunscrevem este artigo, a saber: como a formação ética profissional é construída? De que forma a (des)profissionalização impacta na constituição da ética profissional e quais os desafios enfrentados nesse contexto educacional frente a essas demandas na trajetória docente? Ademais, os construtos teóricos coadunam a partir dos pressupostos de Sacristán (1995), Kleiman (2001), Tardif (2014), Reis (2020) e demais autores, que colaboram para o escopo do texto. Por fim, este artigo elucida que a profissionalização e a ética profissional são elementos fundamentais e integrados às práticas docentes e à formação no enfrentamento à desprofissionalização.
\end{abstract}

Palavras-chave: Ética Profissional. (Des)profissionalização. Formação Docente. Trajetória Docente.

\section{PALAVRAS INICIAIS}

É inquestionável a relevância da função do professor na sociedade. Contudo, a compreensão dessa função ainda é perpassada por uma série de problematizações que incidem na representação que a sociedade tem sobre ela, assim como na própria atuação do profissional docente.

Historicamente, a profissão do professor se constituiu através de mudanças sociais, éticas e políticas, que corroboram às muitas crises e indefinições que hoje cercam a prática docente. Ademais, essas transformações contribuíram para a sua descaracterização, que tem lugar na própria formação inicial e que incide na prática profissional, reverberando nas muitas funções que o docente acaba assumindo, e que, obviamente, não deveriam estar previstas no seu fazer profissional.

De acordo com Nogueira (2008), os professores estão imersos numa crise identitária que engloba toda a esfera de sua formação, em que a dinâmica das intensas transformações e demandas sociais figuram na sua formação e no seu fazer profissional. 
Esses impasses reverberam na ética profissional do professor, o que resulta na sua desprofissionalização docente, que, na contemporaneidade, são atenuados por elementos como as limitantes políticas públicas educacionais e a precariedade da formação docente, conforme aponta Nogueira (2008), ao atentar para a existência significativa de professores que atuam sem a titulação requerida, fatores que condicionam o desenvolvimento da profissão, acarretando, por um lado, numa contínua desconfiança sobre o papel do professor, no seu desprestígio; e, por outro, numa exacerbada exigência da sociedade, muitas vezes culpabilizando os professores por determinadas crises e cobrando-lhes respostas que, quiçá, não Ihes sejam concernentes.

Nesse sentido, torna-se emergente refletir sobre 0 processo de (des)profissionalização' ${ }^{1}$ docente na contemporaneidade, tendo em vista alguns questionamentos sobre como a formação ética profissional é construída; de que forma a (des)profissionalização impacta na constituição da ética profissional e quais os desafios enfrentados nesse contexto educacional frente a essas demandas na trajetória docente.

\section{HISTORICIZANDO A PROFISSÃO: A TRAJETÓRIA DA FUNÇÃO}

A formação docente e a condição da sua profissionalização têm sido objetos de discussões cada vez mais recorrentes no cenário educacional, tendo em vista que são marcadas por intensas crises identitárias, fragilidades formativas, inconsistências políticas e sensação de desconfiança social, o que tem apontado para uma necessidade de ressignificação da profissão mediante as novas demandas que os contextos da vida contemporânea exigem. Por conta disso, a ética também é marcada por essas situações de crise na profissão, já que se configura como elemento fundamental às relações sociais entre docentes e sujeitos dentro e fora do contexto escolar, além de nortear o fazer pedagógico.

Contudo, para se entender as vicissitudes que permeiam os fenômenos de formação e profissionalização docente hoje se faz necessário um estudo mais profundo e detalhado sobre como a profissão foi se constituindo ao longo da história, compreendendo, como aponta Bello (2002), através das concepções de Sacristán (1995) e Popkewitz (1997), que a profissão está entrelaçada pelo seu arcabouço social e histórico, sendo assim, "esta falta de autonomia é fruto, em grande parte, das implicações sociais e históricas construídas em torno da carreira docente" (BELLO, 2002, p. 47). Desse modo, o percurso histórico da constituição docente como profissão contribui para um olhar mais apurado sobre as suas implicações na contemporaneidade.

A gênese de sociedades essencialmente escritas, em que a escrita exerce papel fundamental para a organização do saber, do poder e da ordem, revela o papel do professor. As investigações de Martini e Glasorester (2009) fazem referência às civilizações orientais, nas quais o papel do professor se relacionava com as funções desempenhadas por sacerdotes e escribas, os quais tinham como atividades o conhecimento, o registro e a transmissão das palavras sagradas, assim como formar outros mestres que, mais tarde, ocupariam esses ofícios. Os autores ainda salientam que os judeus dispunham de uma autoridade teológica que, depois, estaria presente na profissão do professor, como também nas sociedades ocidentais, na qual estarão 
imbricadas as relações entre o Estado e a Igreja, que dava a figura do professor uma natureza sagrada, contudo, "o impedia de se perceber como um trabalhador comum" (MARTINI, GLASORESTER, 2009, p.144).

Essas amarras que condicionavam o professor à mera noção de transmissor do conhecimento e expectador de realidades só seriam desfeitas, segundo os autores, com o processo de laicização cultural e a difusão do conhecimento que vem com o advento da imprensa e, logo depois, com a tecnologia da informação, a partir da modernidade.

Embora essa noção sagrada da profissão docente tenha se extinguido, ela deixou resquícios ainda observados atualmente, contribuindo para o não reconhecimento da docência como uma profissão como as outras, assim como para a falta das demarcações essenciais que fundamentam e viabilizam qualquer profissão. Especificamente, nas civilizações africanas e pré-colombianas é possível também observar a função docente por diferentes perspectivas: na investigação de Martín (2011), por exemplo, o autor salienta que a educação tradicional africana, que, nos tempos antigos, se baseava na tradição oral, em muito se difere da noção de educação europeia, com exceção do povo etíope que, desde épocas remotas, possui um ensino centrado na leitura e escrita, através da língua gue'ez.

Segundo o autor, nas comunidades africanas era responsabilidade de todos ensinar as novas gerações. Particularmente, na maioria das civilizações da África précolonial, a educação tradicional se fundamentava em grupos de idosos que, de modo colaborativo, se incumbiam dos processos de desenvolvimento e participação na sociedade dos mais novos: "numa palavra o faz passar do mundo natural da infância ao mundo cultural do homem responsável de sua vida, da natureza e da sociedade" ${ }^{2}$ (MARTíN, 2011, p. 58). Nesse sentido, a formação do sujeito se dava in totum.

O continente novo também guarda uma história muito rica quanto à função do professor e à organização do saber dos povos pré-colombianos. Suárez (2001), por meio de relatos e achados históricos, ratifica a existência de sistemas educativos bem estruturados. $\mathrm{O}$ autor pondera que muitos estudiosos acreditam haver encontrado a organização de um sistema educacional do povo asteca: no conjunto de famílias, denominado Calpulli, em que todos estão ligados por laços sanguíneos, pelo seu território, pela devoção a um mesmo deus e pelo compartilhamento de questões econômicas e históricas. Além disso, a primeira formação se relacionava com os valores familiares, os trabalhos dos pais e com seu propósito no Calpulli.

O desenvolvimento social ocorria a partir dos centros educativos, nos quais as crianças e os jovens, com preeminência dos nobres, eram introduzidos, o Calmécac, casa que reunia as características de escola e templo, em que os mestres, cuja formação era diversificada e ampla, tinham papel substancial na formação de sacerdotes, intelectuais, juízes, governantes e militares. O Telpochcalli, onde atendia grande parte do povo, era o lugar onde os jovens recebiam orientações, formação militar e de trabalho, de forma geral, buscava-se formar trabalhadores para o povo. Por fim, o Cuicacalli, casa em que, segundo Suárez (2011), se localizava dentro do palácio e nas casas dos nobres, com a presença de educadores especiais responsáveis pela formação dos que tinham aptidão artística. Assim como nas tradições dos povos africanos, a transmissão do saber era responsabilidade dos idosos nas comunidades astecas.

Em se tratando dos povos indígenas brasileiros pré-coloniais, é possível vislumbrar um panorama educacional por meio da obra "Modelo Educativos en la 
história de América Latina" (1995), de Weinberg, que recorre às investigações do sociólogo Florestan Fernandes. Na referida obra, o autor ressalta, a partir de Fernandes (1949), a busca pelo equilíbrio na sociedade Tupinambá. Desse modo, havia a preocupação com a perpetuação da herança cultural às novas gerações, alicerçada em três bases: o valor da tradição relativo aos conhecimentos sociais e religiosos, à prática, à repetição como caminho da aprendizagem, como, por exemplo, na forma da herança de seus ancestrais, e às tradições. Segundo Weinberg (1995), os tupinambás apresentavam uma forma social de dominação gerontocrática, sendo a responsabilidade, a honra e o poder de viabilizar os conhecimentos adquiridos por aquela sociedade das gerações mais antigas para as mais novas.

Para muitos investigadores, a Grécia é o lugar onde ocorreram movimentos orientados a um trabalho mais sistemático de docência. Martini e Glasorester (2009) elucidam que é na Paidéia grega que surgem as primeiras discussões sobre os papéis formadores do professor. De acordo com Chauí (2002), os estudiosos da história da Grécia e da filosofia compreendem os sofistas como os "fundadores da pedagogia democrática" (p. 159-160). Aqui, a figura docente assume um caráter específico e sobressalente, com funções características e práticas estruturadas.

É possível perceber os primeiros passos para essa configuração ao conseguirem transmitir uma visão de mundo dentro do contexto em que viviam. Como corrobora Martini e Glasorester (2009), a figura do professor assume diversas nuances: nos tempos homéricos, aparece o therapon, sábios da medicina, das guerras e das armas e das palavras, que respeitavam e disseminavam a ideia da honra heroica, muitas vezes conquistadas com a morte.

Posteriormente, conforme Xavier (2016), a sociedade ansiava pelo desenvolvimento intelectual e pela valorização de sua liberdade. É nessa busca que emerge a figura do professor, os sofistas, como Protágoras, apontados por Chauí (2002) como mestres de uma arte, de uma ocupação. Para a autora, ele era um sábio que detém os conhecimentos sobre algo, com a virtude de fazer-se compreender de modo excepcional por meio da retórica, que, fundamentada nos conhecimentos poéticos, ganha status na sociedade grega. Tais conhecimentos eram exclusivos àqueles que podiam tê-los, já que os sofistas cobravam por seus ensinamentos.

Com Sócrates (470-399 A.C.), o conhecimento se populariza, pois suas práticas docentes se davam mormente em cenários públicos, atingindo aos que detinham pouco ou nenhum poder. Para o filósofo, o importante era uma educação pautada na compreensão individual do sujeito, a sua consciência formativa ética por meio dos conhecimentos adquiridos, base da maiêutica socrática, em que, numa relação dialógica com o estudante, o docente inquiria e instigava, contribuindo para que os próprios sujeitos buscassem e construíssem os conhecimentos, perspectiva presente em muitas concepções educacionais contemporâneas, como as ideias da Pedagogia Libertadora de Paulo Freire. Segundo Xavier (2016), é nesse período que a educação grega alcançou e influenciou o mundo ocidental, além de revelar as contribuições de mais outros dois filósofos: Platão, conhecido como primeiro pedagogo, e Aristóteles.

Com a expansão romana, os escravos gregos cultos eram responsáveis pelo aperfeiçoamento cultural e intelectual dos filhos das classes dominantes, o que era visto 
como essencial para a compreensão das leis e a manutenção das hierarquias. Para Martini e Glasorester (2009), a função do professor é mantida, mas há um maior interesse do Estado nas questões educacionais e, por conseguinte, no professor.

Com o cristianismo, se origina uma relação forte entre o Estado e a Igreja, na qual se veria atingida também a figura do docente. A educação estava sob as concepções religiosas vigentes, monitorando as universidades e todo o processo do saber. Com a Reforma Protestante, de acordo com Martini e Glasorester (2009), tecem-se críticas à relação entre a Igreja e o Estado. Ainda conforme os autores, o trabalho do professor se ampliou no que se refere a democratizar a cultura vigente, por meio da alfabetização, objetivando a leitura da Bíblia.

Desse modo, o ensino ainda se vê no meio dessa forte aliança. Os autores elucidam que, mesmo com o desenvolvimento do mercantilismo nas cidades, culminando no aparecimento de mestres independentes, que se relacionavam com as exigências sociais e culturais da época, de onde nascem as universidades medievais, a presença do controle religioso e imperial ainda é forte. De acordo com Martini e Glasorester (2009), nessa época, buscam-se os conhecimentos científicos e filosóficos através da perspectiva teológico-metafísica dos filósofos gregos, como Platão e Aristóteles, da qual Santo Agostinho e São Tomás, grandes autoridades religiosas, tinham estimada consideração. Em seguida, com o humanismo, o ser humano busca sua liberdade e domínio dos fenômenos da vida, de certo modo, inaugura-se um movimento de privilégio do conhecimento pelas classes aristocratas. Segundo Martini e Glasorester (2009), aqui, a acepção dos sofistas e da Paideia continua na condição de venda do conhecimento e na percepção do docente como mestre.

A série de revoluções ocorridas no mundo ocidental, como a revolução industrial inglesa, revolução francesa e movimentos independentistas das, até então, colônias do continente americano, trouxeram grandes impactos às questões educacionais. Sauter (2012) afirma que isso produziu uma ruptura com a noção absolutista e promoveu delimitações ao poder do Estado. Daí, desencadeia-se a divisão dos poderes, o novo modo de relação entre Estado e sociedade, os direitos individuais.

Com essas mudanças, conforme apontam Martini e Glasorester (2009), outros saberes são alçados: os saberes científicos e técnicos, com a exigência por formar trabalhadores capacitados e qualificados para exercerem suas funções trabalhistas, "a educação se torna negócio do Estado e o professor um funcionário do Estado" (p. 152). Assim, a educação se populariza, torna-se laica, sendo vista como propulsora do desenvolvimento e prosperidade da sociedade.

Especificamente, nos territórios latino-americanos, agora ex-colônias, marcadas pelas cicatrizes da colonização, que criaram indefinições e sensação de não pertencimento ou subexistência, principalmente nas populações subjugadas e aqueles que descendiam da escravidão, é necessário pensar na configuração dada à escola e à figura do professor. Na investigação de Alliaud (1993), sobre a origem da docência na Argentina, a autora traz uma compreensão pertinente sobre isso, na qual a escola seria responsável por solucionar os problemas de ordem moral e intelectual de um povo heterogêneo, nos quais "os filhos refletem as idiossincrasias sociais ou da raça dos pais e a escola deve inculcar-lhe alma nova"3 (p. 3).

Para o autor, o professor, além de garantir a alfabetização, também tinha a função de disseminar uma nova realidade cultural que estava se desenvolvendo. Dessa 
forma, como ele aponta, buscava-se uma espécie de "regeneração social" (p. 4), implicando na ideia de que somente era legítimo o que se transmitia na escola.

Além disso, essa também foi uma realidade no Brasil da época, quando se populariza a educação, trazendo em seu cerne processos de homogeneização e exclusão de saberes, implicando no rechaço àqueles que não se enquadravam no ideal promulgado pela escola.

De acordo com Bello (2002), é nessa época que surgem os primeiros delineamentos sobre a profissão docente contemporânea. Na Europa, vetou-se a possibilidade de ensino sem a licença ou consentimento do Estado, contribuindo para a profissionalização do professor.

Martini e Glasorester (2009) ratificam que, nesse período, o professor se converte em especialista, com a compartimentalização do conhecimento, originando-se duas concepções referentes ao trabalho docente: "uma mais científica e positivista e outra, de tendência mais histórica, humanística e formativa" (p. 152). Segundo eles, essa última compreende a "uma auto-formação pela inserção total e criativa na cultura" ( $p$. 152).

Bello (2002) aponta que houve mudanças no século seguinte no processo de profissionalização docente com a escola normal, com a qual advém um currículo mais robusto e maior demanda estudantil. Recorrendo às reflexões de Nóvoa (1995), Bello (2002), destaca que o professor passa a conviver com diversas dualidades:

Os professores não eram burgueses, mas também não eram do povo; não deviam ser intelectuais, mas deviam deter conhecimento; não eram notáveis locais, mas tinham influência na comunidade; não exerciam o seu trabalho com independência, mas era útil que desfrutassem de certa autonomia (BELLO, 2002, p. 47).

Tais elucubrações, como aponta a autora, contribuíam para que o professor, numa contextualização coletiva, buscasse a sua identidade profissional. Já no século XX, ocorrem movimentos educacionais que, consequentemente, influenciaram a formação e a prática docente, através dos estudos da psicologia e dos avanços na medicina que contribuíram para o desenvolvimento de práticas educacionais inovadoras, pois, a partir desse momento, a educação dispunha de conhecimentos mais específicos sobre as questões biológicas e comportamentais aliados à busca pelo conhecimento das transformações sociais.

De acordo com Martini e Glasorester (2009), nessa época, também se observa a divisão desigual de gênero na profissão, em que as professoras recebiam menos e os professores recebendo mais, sendo estes últimos, quase sempre, responsáveis pela docência no ensino superior. Bello (2002) assevera que, apesar dessas problemáticas, é um momento em que a profissão alçou algumas conquistas como a criação de associações, a criação da escola normal e a obrigatoriedade de uma licença para dar aulas, o que também ocorreu no Brasil.

Segundo Freitas (2003), os anos finais do século XX foram marcados por grandes pautas sobre a formação do professor, a partir de reformas educacionais, culminando em políticas formativas centradas em habilidades e competências, além da 
BORGES, C. B. S.; SANTOS, I. N. C. dos.

formação prática. Com isso, para a autora, originavam concepções de desprofissionalização do professor, haja vista a responsabilização individual por seu aperfeiçoamento profissional.

Apesar de grandes conquistas para a formação docente, no que se refere ao caráter sócio-histórico da formação e à importância de uma formação mais ampla quanto ao conhecimento do espaço escolar e da própria sociedade para a atuação docente, a autora acrescenta dizendo que "o abandono da categoria trabalho pelas categorias da prática, prática reflexiva, nos estudos teóricos de análise do processo de trabalho" (Freitas [2003], p. 1096) são elementos que contribuíram para o delineamento de políticas educacionais somente voltadas à qualidade instrumental e conteudista, orientando transformações curriculares, Parâmetros Curriculares Nacionais e avaliação voltados a "uma perspectiva produtivista e unidimensional [Frigotto, 1996], em detrimento da formação humana multilateral [Freitas, 2000]" (FREITAS, 2003, p. 1097).

Com o fim da Segunda Guerra Mundial, Pátaro (2018) indica que se intensificou a ideia de educação como agente de prosperidade. A corrida tecnológica e a globalização promoveram uma nova ordem mundial, em dimensão social, econômica e cultural, com intercâmbios mais intensos e integralização dos países. Esses fatores também colaboraram para processos educacionais, culminando na gratuidade e democratização da educação, na formação massiva de professores e investigações que pudessem contribuir com o processo formativo docente.

Desse modo, houve um crescimento ao acesso educacional, principalmente a nível universitário, oriundo de movimentos de combate à desigualdade e exclusão de acesso à educação, muitos legalizados constitucionalmente, através das políticas educacionais e políticas públicas afirmativas, embora ainda haja uma longa jornada a ser trilhada no que tange à democratização do ensino. Também marcam a educação contemporânea uma série de incertezas e desafios que incidem na formação e prática docente e que fizeram o professor atual encontrar-se numa rede de inquietações, entre as quais estão: o forte engajamento tecnológico, a necessidade de compreender melhor estudantes com condições comportamentais e de aprendizagem específicas e a exigência por ressignificar o processo de ensino atendendo às demandas da sociedade $e$ do perfil do aluno do século XXI.

Além disso, a profissão enfrenta aspectos adversos no seu cotidiano, alguns contrariamente naturalizados como: o sucateamento e desconfiança da profissão por parte da sociedade, as hipérboles e as arbitrariedades que passaram a fazer parte da sua prática docente, como a excessiva carga horária destinada às demandas da profissão, a exaustiva jornada de trabalho, a extrapolação funcional, a desigualdade na relação da prática trabalhista, o pagamento pela exercício docente, as condições insalubres e opressoras de trabalho, como a violência física e psicológica, as pressões, a falta de maior apoio material e imaterial e de assistência e incentivo à profissão e políticas educacionais que subalternizam a profissão.

\section{FORMAÇÃO DOCENTE E ÉTICA PROFISSIONAL}

Sob a égide da construção de uma sociedade contemporânea política e socialmente mais justa, encontram-se as diversas crises identitárias, dentre elas, está a ética profissional do docente e sua formação, pois a competitividade, a busca de 
benefícios individuais em detrimento do coletivo e uma postura apolítica na profissão contribuem para o enfraquecimento e fragilidade da ética profissional na formação docente. Nesse sentido, um dos requisitos a ser pensado sobre essas demandas é como a formação profissional ética docente é construída, se há uma discussão para as demandas coletivas desses profissionais e de que forma esse agir coletivo impacta positivamente ou não na construção da ética profissional. Esses questionamentos são de extrema relevância hoje, pois os docentes estão imersos em diversos conflitos e enfretamentos que circundam a sua formação profissional, sendo questionado o seu verdadeiro papel social e político na formação cidadã dos educandos para além dos conteúdos formais das disciplinas. É nessa reflexão social, política e de ética profissional que se constrói essa seção, pois compreendemos que a formação ética profissional docente perpassa por uma dimensão coletiva de ações colaborativas e de transformações políticas que beneficiem a todos, especificamente, aqui, os educadores.

Desse modo, compreender a formação e o desenvolvimento docente para além e, ao mesmo tempo, correlacionados às palavras de Nóvoa (1997), no que concerne às dimensões coletivas na formação profissional docente, deve atender às demandas dos saberes e práticas educativas. Entretanto, corroboramos a ideia de também relacionar-se com as demandas sociais e políticas de ser e estar na profissão como sujeito protagonista na construção de políticas educacionais. Igualmente, a ética profissional é um quesito posto em "cheque" na formação desse docente, seja na ausência e/ou fortalecimento dela, pois a compreensão desta determina o agir docente dentro e fora da comunidade escolar, a qual reverbera no engajamento do ensino e aprendizagem de si e do outro e, sobretudo, na ciência dos direitos e deveres de sua profissão.

Ademais, o docente é um ator social e político na comunidade escolar e, como tal, necessita compreender as exigências que regem sua profissão, no que concerne aos direitos e deveres, plano de carreira, conselhos educacionais, Fundo de Desenvolvimento da Educação Básica - FUNDEB, dentre outros órgãos e leis, que envolvem o sistema educacional. É urgente que o professor se aproprie desses conhecimentos para valorização do seu fazer docente, principalmente, para uma conduta ética profissional pautada em práticas democráticas e emancipatórias na relação com o outro (trabalhadores de educação, discentes, comunidade escolar, secretarias e demais), questões que estão para além do âmbito pedagógico.

Nesse sentido, a identidade docente está coadunada com a identidade política, pois suas aspirações individuais se relacionam com as coletivas, pois nelas estão contidas uma formação docente e profissional democrática, ética e política, conforme apontam Santos, Spagnolo e Stöbaus (2018):

Saber sobre como o outro se sente, faz e procura ajuda a identificar suas próprias necessidades, anseios e aspirações, contribui para o autoconhecimento e, consequentemente, para perceber melhor o seu lugar no coletivo e a importância das ações individuais para o crescimento do grupo no trabalho colaborativo (SANTOS, SPAGNOLO E STÖBAUS, 2018, p.80). 
Compreendemos que o conceito de ética é atravessado por diversas definições e argumentos, pois está pautado na regulação das relações sociais, no comportamento do homem com o meio social, a partir do bem-estar individual e coletivo, seus valores e as reflexões sobre eles. Ética é uma palavra de origem grega, relacionada ao termo ethos, conforme o dicionário online Michaelis ${ }^{4}$, refere-se aos valores, princípios que fundamentam a vida humana, no que tange ao bem e ao mal, à obrigação e ao dever. Esses valores, ou princípios, são universalmente válidos e norteiam o comportamento humano. Outra definição é a do filósofo Aristóteles, para quem a ética está associada à felicidade, ou seja, ao bem-estar, uma construção pessoal do indivíduo. Além disso, temos a ética na perspectiva kantiana, na qual as ações do homem devem ser guiadas pela razão e independe da cultura inserida.

Nessa perspectiva, a ética está associada ao bem-estar do outro e de si, enquanto sujeito socialmente constituído pela razão e virtudes, sendo assim, a ética profissional dos docentes associa-se por uma dimensão de colaboração, acolhimento e solidariedade com as pessoas no convívio de trabalho. Dessa forma, corroboramos uma ética profissional pautada na empatia, de acordo com as discussões de Santos, Spagnolo e Stöbaus (2018):

\footnotetext{
A colaboração caminha conjuntamente com o processo de empatia. Para que as pessoas (nesse caso, os professores, seus estudantes, a equipe diretiva e possivelmente até os pais) possam desenvolver um trabalho em conjunto, de modo a respeitar as diferenças e valorizar os processos de construção, com aceitação das divergências e convergências (também em um sentido de uma educação mais inclusiva), é essencial conhecer e entender melhor o outro. Inclusive, tentando colocar-se empaticamente em seu lugar. Isso demanda compreender as necessidades, dificuldades, a maneira de pensar e agir do outro. Existe, ainda e talvez em supremacia, o processo empático consigo mesmo (SANTOS; SPAGNOLO E STÖBAUS, 2018, p.80).
}

Por outro lado, as ponderações supracitadas incidem também em um profissional reflexivo, no que se refere a entender os documentos oficiais que regem a profissão, por exemplo, uns dos princípios da Lei de Diretrizes e Bases - LDB n 9.324/96, que determina, no inciso VII, a "valorização do profissional da educação escolar e no que concerne ao estudante determina no artigo 35, inciso III "o aprimoramento do educando como pessoa humana, incluindo a formação ética e o desenvolvimento da autonomia intelectual e do pensamento crítico". Essas ponderações são de extrema relevância para construção e ressignificação enquanto sujeito docente ético. Salientamos que esse agir ético, por muitas vezes, é posto em dúvida por diversas condicionantes do ambiente do trabalho, dentre elas: a desvalorização, a busca de benefícios próprios, as opressões, os dilemas e tensões, dentre outras, que contribuem para a quebra dos princípios éticos e morais na conduta do docente. Portanto, discutir a relação ética profissional associada à ética pessoal no sistema educativo é pertinente por essas relações serem complementares e, sobretudo, pelo constante diálogo estabelecido por elas nos espaços educativos.

Além disso, propôr uma formação sobre as questões éticas para o professor tanto na formação inicial quanto na continuada colaboram para desconstrução de 
equívocos e posturas desalinhadas ao agir docente e à compreensão desse princípio. Assim, afirmamos que a formação ética profissional do docente é de natureza constitutiva e que agrega as dimensões pessoais, sentimentais e interacionas, dentre outras, de forma integradora, conforme aponta Caetano e Silva (2009):

\begin{abstract}
Esses trabalhos de natureza empírica dão-nos a conhecer que os professores, quando lhes é pedido para se exprimirem acerca do que pensam que é ser professor, definem a sua profissão como uma actividade constitutivamente ética: ética porque o professor deve agir na observância de um conjunto de princípios de natureza moral e também porque o que se espera do professor é que ele recorra a uma estratégia, desenvolva um método e disponha de recursos para promover a formação ética dos alunos (CAETANO E SILVA, 2009, p.50).
\end{abstract}

Agregado a isso, o professor necessita repensar sua formação e sua prática docente de forma reflexiva e emancipadora, através das vivências e experiências profissionais na comunidade escolar. Desse modo, é pertinente adequá-las e ressignificá-las em consonância às políticas públicas existentes e à ética profissional. Recorrendo à proposta de Magalhães (2001), o "professor etnógrafo" é aquele, portanto, que reflete os problemas e busca soluções a partir de um processo de engajamento e investigação com o envolvimento dele e dos alunos.

Outra acepção da autora é a "(auto)formação do professor via letramento", ou seja, o processo de desenvolvimento crítico acerca da dimensão pessoal e profissional. $\mathrm{E}$, por fim, a autora destaca também o professor reflexivo, aquele que se distancia e se aproxima de sua prática de forma reflexiva.

Em síntese, é importante ressaltar que a formação docente e a ética profissional são elementos interligados e interdependentes à luz de um viés político e social que confronta os dilemas e tensões inerentes à docência. Para tanto, esses tensionamentos são genuínos, pois buscam romper com a desprofissionalização e/ou mobilizam ações para a valorização profissional docente, temas estes que serão discutidos na seção seguinte, no que concerne a apontar os caminhos e conflitos acerca desse tema.

\title{
A (DES)PROFISSIONALIZAÇÃO DOCENTE E AS IMPLICAÇÕES NA FORMAÇÃO PROFISSIONAL
}

Nos tempos atuais, a docência é alvo de críticas na sociedade por conta do desconhecimento acerca da profissão. Considerando a desinformação sobre as diversidades, os dilemas encontrados em uma sala de aula, os conhecimentos que são mobilizados para esse exercício, além das diferentes funções que muitas vezes os professores são obrigados a incorporar na sua prática profissional, muitas das quais não estão previstas no perfil constitutivo da profissão, incidem diretamente na desprofissionalização docente. Essas situações são ocasionadas devido à desprofissionalização do seu desprestígio, somado ao fato de muitas vezes os profissionais não compreenderem a função social e política da docência na sociedade. 
É extremamente importante deixar claro a problemática que acarreta ao docente assumir diversas demandas, tais como pai, mãe, psicólogo, tio/tia, dentre outras, sendo que estas, com certeza, não fazem parte do arcabouço profissional do professor. Por conta desse imaginário, temos outro impasse: além do dilema da profissionalização incipiente e forjada, a ideia de que qualquer pessoa pode ser "professor".

Conforme supracitado anteriormente acerca das exigências postas para o professor, elas colaboram para a desprofissionalização e contribuem para uma "cortina de fumaça", no que concerne à invisibilidade dos problemas profissionais enfrentados, dentre eles: a carga horária excessiva, desvalorização financeira, a falta de recursos didáticos, pedagógicos e de infraestrutura e outras necessidades inerentes à profissão.

Todas essas adversidades são fruto de uma história de desvalorização e desumanização da profissão construída ao longo do tempo por ausências e/ou descumprimento das leis, no que diz respeito à formação profissional docente. Tendo em vista esses embates, é importante o professor "tomar as rédeas" do agir docente, ou seja, compreender que é agente educacional, além de ser agente social e político, e tudo isso está imbricado ao movimento de profissionalização.

Em consonância com Souza (2016), percebe-se um desmonte na profissão docente, ou seja, um projeto de cancelamento dos saberes profissionais e importância do professor no sistema educacional, transformando-o em um sujeito dispensável.

O engajamento do professor nas lutas por suas causas legítimas é imperativo, pois estas contribuem para a desmitificação dos estereótipos. Por outro lado, compreender a subjetividade do sujeito envolvido nesse processo de profissionalização é salutar, devido as vivências e experiências desses profissionais fortalecerem as ações e possibilitarem, conforme diz Gaddoti (2007), a construção de uma luta coletiva comum a todos. Partindo dessas ponderações, corroboramos o diálogo acerca da subjetividade do professor, de acordo com Tardif (2014):

[...] um professor de profissão não é somente alguém que aplica conhecimentos produzidos por outros, não é somente um agente determinado por mecanismos sociais: é um ator no sentido forte do termo, isto é, um sujeito que assume sua pratica a partir dos significados que ele mesmo lhe dá, um sujeito que possui conhecimentos e um saber-fazer provenientes de sua própria atividade e a partir dos quais ele estrutura e a orienta (TARDIF, 2014, p.230).

É bom ressaltar aqui que a ideia não é estabelecer o certo e o errado, o político e o apolítico, mas sim entender que a profissionalização do professor engloba várias dimensões. É muito importante que o professor entenda, discuta e reflita acerca do contexto educacional, da sua formação e das suas práticas docentes para o cumprimento das políticas públicas existentes no que tange à valorização profissional e, sobretudo, no rompimento com a desprofissionalização. Nesse sentido, o pensamento coletivo no embate das ideias redutoras sobre o ensino e, consequentemente, sobre a docência é indispensável, pois, na conjuntura atual, há um esfacelamento relativo ao sistema educativo e aos trabalhadores da educação. 
As palavras "emancipação" e "transgressão" fazem parte da natureza profissional, visto que através delas configura-se o status de verdadeiros atores políticos no ensino, na comunidade escolar e nos espaços de fomento as aprendizagens e saberes. Mediante a ponderação sobre ser profissional, Imbernón (2002) aponta:

[...] ser um profissional da educação significa participar da emancipação das pessoas. O objetivo da educação é ajudar a tornar as pessoas mais livres, menos dependentes do poder econômico, político e social. E a profissão de ensinar tem essa obrigação intrínseca (IMBERNÓN, 2002, p. 27).

A profissionalização está intrinsicamente relacionada à identidade docente, elas não se desassociam, ao contrário, se incorporam e constituem a docência e, sobretudo, os saberes implicados a ela. É notório, atualmente, sob o viés da identidade profissional, compreender que esta depende de um "olhar" mais crítico e solidário para o seu fortalecimento e anseios dos professores, assim, é possível transgredir as fronteiras da desprofissionalização, a qual é validada pelo desprestígio e controle social das políticas públicas do Estado.

Por essas razões, assumir o protagonismo e o autocuidado é importante no processo de profissionalização, associado também à necessidade de uma formação contínua, pois, dessa maneira, minimizam-se as fragilidades, as crenças equivocadas e os estereótipos impostos à profissão docente.

É importante ressaltar, na atividade profissional, os elementos tecnicista, cognitivo e social, uma vez que são estratégicos, contudo, de acordo com Tardif (2014), a subjetividade atravessa o sujeito pessoal quanto profissional, além disso, adicionamos o político também. Em suma, os desafios profissionais são inúmeros e o caminho para dissipar esses obstáculos é ser um docente reflexivo e ciente do seu papel social e político na sociedade.

\section{PALAVRAS FINAIS}

Neste artigo, buscamos discutir e refletir acerca da trajetória docente pela historicização, assim como a ética profissional e a (des)profissionalização e os impactos, desafios e dilemas ainda evidenciados na contemporaneidade.

A subalternização da profissão, o imaginário simbólico do papel docente e a fragilidade da ética profissional são demandas históricas que se perpetuam ainda no contexto atual, embora existam muitas frentes de resistências para a desconstrução das ideias reducionistas.

Assim, ao retomar o processo evolutivo da constituição da figura do professor, observa-se que esta se construiu a partir da ideia do sujeito transmissor de conhecimento, uma missão ou sacerdócio, algo sagrado e vocacional. Todas essas representações incidem no profissional docente contemporâneo. Por conta disso, há diversas implicações na ascensão da carreira, nos investimentos de formação docente, na garantia do cumprimento de políticas públicas no que concerne ao professor. 
Diante das ponderações mencionadas anteriormente, adicionamos que a construção histórica da figura do professor e suas interfaces nos países africanos pela oralidade e, posteriormente, pela escrita, os saberes indígenas, as concepções romanas e gregas, dentre outros, contribuíram para os caminhos da formação profissional. Entretanto, na contemporaneidade, muitas perspectivas se veem contextualmente deslocadas, e é urgente transgredir visões ultrapassadas para a comunidade escolar atual, pois somos outros sujeitos, com diferentes vivências, narrativas, experiências no que corresponde à profissionalização.

E, nesse sentido, compete sermos atores sociais, políticos e cidadãos docentes que busquem fortalecer a profissão com o uso da ética e do bem comum coletivo e, para além disso, posturas e ações políticas que fomentem uma formação democrática, solidária e emancipatória com vistas à valorização profissional. Dessa maneira, é possível romper com a desprofissionalização que é um estigma juntamente com a culpabilidade e a responsabilização postas a nós pelas mazelas educacionais e por extensão, sociais, frutos de um esfacelamento das políticas públicas educacionais promovido pelo Estado.

É imperativo desconstruir a ideia do sacerdócio, da doação, do trabalho que se limita à prática por amor, pois esses pensamentos cooperam com a desvalorização profissional tanto pelo Estado quanto pela sociedade, os quais acreditam que não devem investir no profissional docente. Por sua vez, esses estereótipos equivocados acarretam fatores como a baixa remuneração, péssimas condições de trabalho, formação continuada incipiente, carga horaria excessiva, ausência da exigência de formação e comprovação para o exercício da profissão e demais implicações concernentes ao professor.

Em suma, a profissionalização e a ética profissional são indissociáveis e caminham juntas com a formação docente. Portanto, ter a clareza da importância desses elementos na contemporaneidade favorecem ações efetivas e significativas nas políticas públicas profissionais e no seu cumprimento em consonância com os documentos oficiais e, especialmente, empodera o profissional quanto à sua formação e prática, possibilitando ao sujeito questionar e confrontar posturas que privilegiem sua desprofissionalização.

THE INTERFACES OF TEACHING FIGURE: PATHS AND MISPATHS OF THE TEACHING (DE)PROFISSIONALIZATION

ABSTRACT: The purpose of this article is initially to discuss about the interfaces of teaching figure, with regard to professional ethics, the process of (de)professionalization and the paths and mispaths traveled, in addition aims to present the paths of such training pointing out the dilemmas, possibilities, clashes and adjustments. In this sense, we seek to clarify and respond to these tensions, which are strongly evidenced in contemporary times. Therefore, some questions circumscribe this article, namely: how professional ethical training is constructed; how (de)professionalization impacts on the constitution of professional ethics and what are the 
challenges faced in this educational context in the face of these demands in teaching trajectory. In addiction, the theoretical constructs are based on the assumptions of Sacristán (1995), Kleiman (2001), Tardif (2014), Reis (2020) and other authors who collaborate for the scope of this text. Finally, this paper elucidates that the profissionalization and professional ethical are fundamentals elements and integrates teaching practices and their tranning in the confrotation with deprofissionalization.

KEYWORDS: Professional Ethics. (De)profissionalization. Teacher Training. Teaching Trajectory.

\section{LAS FACETAS DE LA FIGURA DEL PROFESOR: CAMINOS Y DESCAMINOS DE LA (DES)PROFESIONALIZACIÓN DOCENTE}

RESUMEN: El artículo que se presenta inicialmente tiene como finalidad discutir sobre las facetas de la figura docente, en lo que atañe a la ética profesional, el proceso de (des)profesionalización y los caminos y descaminos atravesados, así como se objetiva presentar los recorridos de esa formación apuntando los dilemas, posibilidades, conflictos y ajustes. En ese sentido, buscamos aclarar y contestar esas tensiones, las cuales son fuertemente evidenciadas en la contemporaneidad. Por lo tanto, algunos cuestionamientos circunscriben este artículo, a saber: como la formación ética profesional es construida; de qué modo la (des)profesionalización impacta en la constitución de la ética profesional y cuáles son los desafíos enfrentados en ese contexto educacional frente a esas demandas en la trayectoria docente. Además, los constructos teóricos coinciden a partir de los presupuestos de Sacristán (1995), Kleiman (2001), Tardif (2014), Reis (2020) y otros autores que contribuyen con el propósito de ese texto. Por fin, este artículo elucida que la profesionalización y la ética profesional son elementos fundamentales e integrados a las prácticas docentes y a la formación, en el enfrentamiento a la (des)profesionalización.

PALABRAS-CLAVE: Ética Profesional. (Des)profesionalización. Formación Docente. Trayectoria Docente.

\section{NOTAS}

1 - A expressão (des)profissionalização é usada, neste texto, entre parentênses, dada a percepção de que a profissionalização e desprofissionalização docente, atualmente, estão imbricadas, devido aos processos de crises identitárias, sociais e polítcas na formação profissional e da ética docente, ou seja, ocorrem de forma concomitante.

2 - Tradução nossa do original: "En una palabra le hace pasar del mundo natural de la infancia al mundo cultural del hombre responsable de su vida, de la naturaleza y de la sociedad" (MARTíN, 2011, p. 58).

3 - Tradução nossa do original: "los hijos reflejan las idiosincrasias sociales o de raza de los padres y la escuela debe inculcarles alma nueva" (ALLIAUD, 1993, p. 3).

4 - Informações extraídas do dicionário online Michaelis. Disponível em: <https://michaelis.uol.com.br/moderno-portugues/busca/portugues-brasileiro/\%C3\%A9tica/> Acesso em 05 de ago. 2020. 
BORGES, C. B. S.; SANTOS, I. N. C. dos.

\section{REFERÊNCIAS}

ALLIAUD, A. Los maestros y su historia: los orígenes del magisterio argentino. Biblioteca Política Argentina. Buenos Aires: Centro Editor de América Latina, 1993.

BELLO, I. M. Formação, profissionalidade e prática docente: relatos de vida de professores. São Paulo: Arte \& Ciência, 2002.

BRASIL. Ministério da Educação. Lei de Diretrizes e Bases da Educação Nacional. Lei n. 9.394/96. Disponível em: http://www.planalto.gov.br/ccivil_03/Leis/L9394.htm. Acesso em: 10 jul. 2020.

CAETANO, A. P. SILVA, M. de. L. Ética profissional e Formação de Professores. Revista de Ciências da Educação, São Paulo, n. 8, jan/abr, p.49-60, 2009.

CHAUÍ, M. de. S. Introdução à história da Filosofia Vol.1: dos pré-socráticos a Aristóteles. São Paulo: Companhia das Letras, 2002.

FERREIRA, M. C. F. D.; REICHMANN, C. L.; ROMERO, T. R. de. S. (Orgs.). A Construção Identitárias de professores de Línguas. In: SOUZA, E. C. de. Profissionalização, fabricação de identidades e trabalho docente: alguns apontamentos teóricos. Campinas-SP: Pontes editores, 2016, p. 15-32.

FREITAS, H. C. L. de. Certificação docente e formação do educador: regulação e desprofissionalização. Educação e Sociedade, Campinas, vol. 24, n. 85, p. 1.095-1.124, dezembro 2003.

GADOTTI, M. A escola e o professor: Paulo freire e a paixão de ensinar. São Paulo: Publisher Brasil, 2007.

IMBERNÓM, F. Formação docente e profissional: formar-se para a mudança e a incerteza. 3. ed. São Paulo: Cortez, 2002.

KLEIMAN, A. K. (org). A formação do professor: perspectiva da Linguística Aplicada. Ed. Mercado das Letras: Campinas, SP, 2001.

KLEIMAN, A. K. Formação do professor: retrospectivas e perspectivas da pesquisa. Ed. Mercado das Letras: Campinas, SP, 2001. p. 239-259.

KLEIMAN, A. K; MAGALHÃES, L. M. Modelos de educação continuada: os diferentes sentidos na formação reflexiva docente. Ed. Mercado das Letras: Campinas, SP, 2001. p. 39-65. 
MARTíN, P. A. S. De la educación tradicional africana a la escuela actual en África subsahariana. TABANQUE - Revista pedagógica, Valladolid - España, n. 24, p. 5368, jun, 2011.

MARTINI, R. M. F.; GLASORESTER, P. R. C. Trabalho do professor: do dizer das tradições a emergência dos sentidos contemporâneos. História da Educação (UFPel), Pelotas, v. 13, n. 28, p. 135-157, mai/ago, 2009.

NOGUEIRA, M. O. G. O processo de profissionalização-desprofissionalização docente: a formação e o trabalho dos professores no Brasil. In: VIII Congresso Nacional de Educação EDUCERE/ Formação de professores- Ed. Internacional, Brasil, 2008. p. 4720-4732.

NÓVOA, A. Os professores e sua formação. Lisboa: Dom Quixote, 1997.

PÁTARO, R. F. As revoluções educacionais na história da educação e a democratização da escola básica no Brasil: implicações para os objetivos da escola na contemporaneidade. Revista de História da UEG, Goiás, v. 7, p. 197-222, 2018.

SANTOS, B. S.; SPAGNOLO, C.; STÖBAUS, C. D. O desenvolvimento profissional docente na contemporaneidade: implicações transformadoras para o ser e para o fazer. Revista Educação, Porto Alegre, v. 41, n. 1, p. 74-82, jan/abr. 2018.

SAUTER, G. O. Génesis de los sistemas educativos nacionales en el mundo occidental. In: FERRER, A. T.; SAUTER, G. O.; FERNÁNDEZ, F. S. (coords.). Historia de la educación (Edad Contemporánea). Madrid-España: UNED, 2012. p. 21-43.

SUÁREZ, C. A. Sobre la Educación precolombina. Revista de Teoría y Didáctica de las Ciencias Sociales. Mérida, Venezuela, n. 6, p. 137 - 156, jan/dez, 2001.

TARDIF, M. Saberes docentes e formação profissional. 15. ed. Petrópolis. RJ. Vozes. 2013.

TARDIF, M. Os professores enquanto sujeitos do conhecimento. ed. Petrópolis. RJ. Vozes. 2014. p. 227-244.

TARDIF, M. Saberes profissionais dos professores e conhecimentos universitários. ed. Petrópolis. RJ. Vozes. 2014. p.245 - 276.

TARDIF, M. Ambiguidade do saber docente. ed. Petrópolis. RJ. Vozes. 2014. p. 277-303.

WEINBERG, G. Modelos Educativos: en la historia de América Latina. Buenos Aires: UNESCO-CEPAL-PNUD. AZ Editora, 1995. 
BORGES, C. B. S.; SANTOS, I. N. C. dos.

XAVIER, A. R. História e Filosofia da Educação: da Paideia grega ao pragmatismo romano. Revista Dialectus, Ceará, n. 9, set/dez, p. 81 -99, 2016.

Cintia BÁrbara SILVA Borges: Mestra em Língua e Cultura pela Universidade Federal da Bahia - UFBA (2018), Especialista em Língua Inglesa pela Universidade Salvador Unifacs (2012). Possui graduação em Letras vernáculas com Língua Inglesa e Respectivas Literaturas pelo Centro Universitário Jorge Amado (2007), Participante do Grupo de Pesquisa do CNPq Decolonidade, Linguagem, Identidade e Educação- DECOLIDE. Atualmente é Professora de Língua inglesa na União Metropolitana de Educação e Cultura - UNIME e do Colégio Municipal Profa. Daúlia Angélica.

Orcid: https://orcid.ors/0000-0002-6692-5634

E-mail: cintiabarbara11@hotmail.com

Itamaray Nascimento Cleomendes dos Santos: Mestra e doutoranda em Língua e Cultura pelo Programa de Pós-Graduação em Língua e Cultura da Universidade Federal da Bahia - PPGLinC/UFBA. Licenciada em Letras/Língua Espanhola e Literaturas de Língua Espanhola pela Universidade do Estado da Bahia - UNEB, Campus I (2015). É integrante do Grupo de Pesquisa Decoloniade, Linguagem, Identidade e Educação DECOLIDE.

Orcid: https://orcid.org/0000-0002-5930-6720

E-mail: itamaray.nascimento@hotmail.com

Este periódico utiliza a licença Creative Commons Attribution 3.0, para periódicos de acesso aberto (Open Archives Initiative - OAI). 